\title{
Experimental Research of the Overvoltage in the Insulated Neutral Network
}

\author{
Vitalijus Gvozdas, Department of Electric Power System, Kaunas University of Technology, \\ Povilas Valatka, Department of Electric Power System, Kaunas University of Technology
}

\begin{abstract}
The isolated neutral network isolation resistance is often affected by the lightning discharge surge to the line cables or towers. Several overvoltage waves are maid at the moment of the lightning discharge surge. It is dangerous for the devices because at the very short time period the isolation of the device is affected by the surge impact twice or even more. The analysis of the experimentally registered lightning discharge induced overvoltage transients effect from the lightning influence to the power line till the power line disconnection were analyzed in this work. Estimation of the overvoltage characteristics to the isolation resistance was made.
\end{abstract}

Keywords: Isolated neutral network overvoltage, atmospheric overvoltage registration, integral characteristics.

\section{INTRODUCTION}

Due to various commutation or side effects the voltage in power line during transients could increase permissible operating limit. Such voltage increase (overvoltage) is dangerous for the reliable work of device isolation. The level of the overvoltage depends on its source. Transients in the power line could originate from - switching commutations, short circuit disconnection, formation resonance or Ferro resonance. A high-risk overvoltage in the isolated neutral networks could be created by the lightning strike to the closest towers. A lightning surge is covered by the current flow through the substation overvoltage arresters.

Overvoltage size depends upon power line length, configuration, structure, workload and voltage level in the line. Peak level of the overvoltage is determined experimentally, by registration, or modeling transient calculations for the various isolated neutral network workmodes.

Measurements of the $10 \mathrm{kV}$ isolated neutral network voltage transformers, which are affected by the single phase fault and overvoltage, was performed in this work. The measurements where made at four $110 / 10 \mathrm{kV}$ substations. It was made analysis of the registered short transients in $10 \mathrm{kV}$ power network which affect device isolation resistance. Transient's character and their impact for the $10 \mathrm{kV}$ voltage transformer isolation resistance was determined.

\section{THE EVALUATION OF OVERVOLTAGE EXPOSURE LIMIT VALUES AND DURATION}

The isolation resource use characteristic can be arranged in accordance with the integral overvoltage impact characteristics, including its duration in the entire overvoltage operating range.
The marginal overvoltage exposure characteristics are divided in three areas. The zones are separated according to the test voltages (Fig. 1).

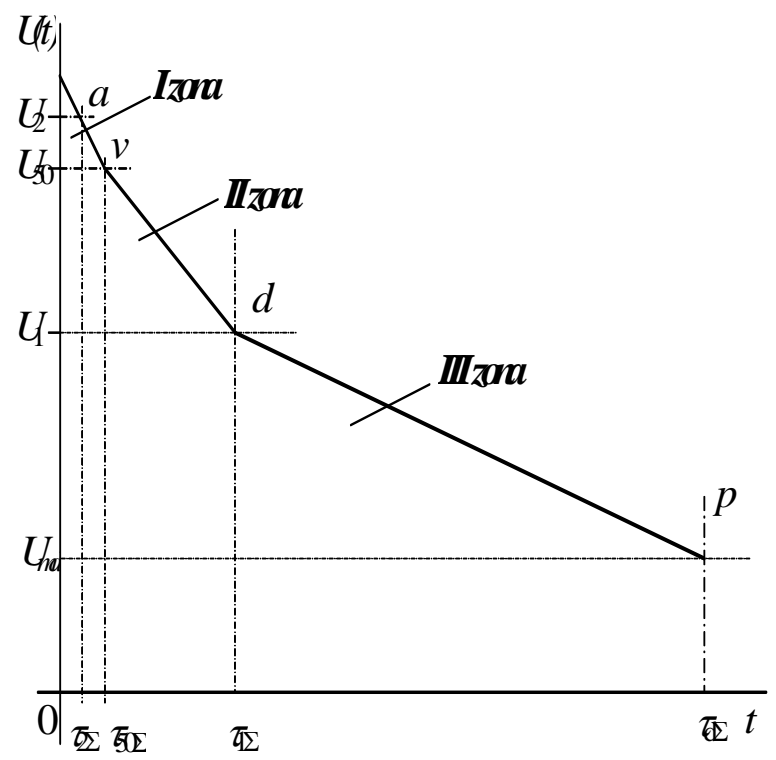

Figure 1. Evaluation zones of the registered overvoltage.

High amplitude short impulse overvoltage zone is between short and full test voltage. In this area overvoltage are caused by a lightening discharge. Switching and atmospheric overvoltage zone is between full test pulse voltage and 1 minute $50 \mathrm{~Hz}$ frequency test voltage. In this area overvoltage are caused by lightning discharge, switching or ferroresonance phenomena. Earth fault and short-term gains, as well as switching overvoltage zone is between 1 minute $50 \mathrm{~Hz}$ frequency test voltage and the long-term maximum permissible voltage. According this electrical equipment insulation marginal reliable performance characteristic can be arranged $[2,3]$.

\section{APPLICATION CHARACTERISTICS OF THE OVERVOLTAGE REGISTRATION}

A four - channel overvoltage recorder was connected to the $10 \mathrm{kV}$ voltage transformer secondary "star - connection" winding (three channels). One channel was connected to the open delta (Fig. 2). A recorder was triggered by the zero sequence voltage level because during any transient (power line actuation, one phase fault, short circuit, etc.) the voltage level increases apparently. 


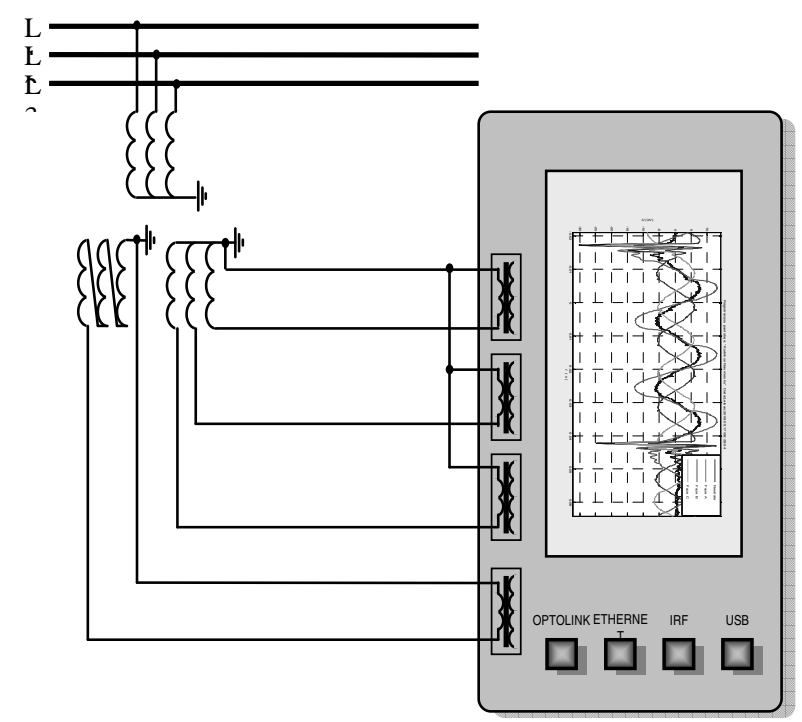

Figure 2. Overvoltage recorder connection diagram.

A recorder starts to record transient when open - delta voltage increases over determined level. An event is recorded with a prehistory. Such registration could show an origin condition of the primary process. One full recorded event is shown in Fig. 3. During analysis process the discretion step is reduced and the detailed process parameters are established.

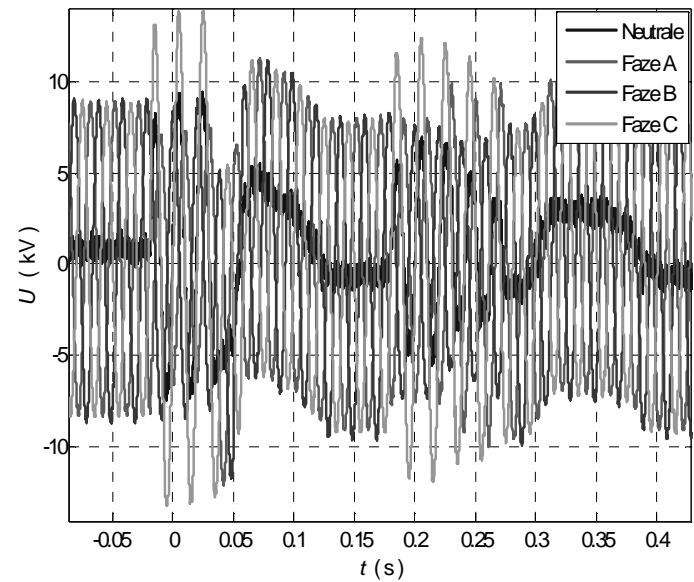

Figure 3. A registered event.

Registrations where made in those $10 \mathrm{kV}$ substation where were registered a power line break - downs affected by overvoltage. A recorder was connected in the $10 \mathrm{kV}$ isolated neutral network. Registration leased for the three weeks. It was registered several overvoltage transients of the lightning strike to the power line.

\section{OVERVOLTAGE REGISTRATION INDUCED BY THE LIGHTNING SURGE}

It was registered full overvoltage transient event induced by the lightning surge. After the main lightning surge repeated surge impulses mostly forms after $0.03-0.05 \mathrm{sec}$, with their own suddenly settled leaders. We can count from $2-3$ till 10, very rare - even more repeated surge impulses during 1 second [1].

During experimental recordings full event was registered from the first lightning surge overvoltage till the power line disconnection. Two - phase short circuit was formed in the power lines, which overgrow to the three - phase short circuit after the second impulse made by a lightning surge overvoltage. Full multifold surge induced transient oscillogram shown in Fig. 4.

A registered event length lasts $1.1 \mathrm{sec}$. During lightning surge it was formed 7 current peaks to the power line.

Voltage dips in phases and neutral where induced by the first current peak of a lightning surge. Two - phase short circuit was formed after induced overvoltage of the first lightning surge impulse (Fig. 5).

After $59 \mathrm{~ms}$ the second lightning impulse was registered in the event again (Fig. 6). An induced overvoltage in the phase reduces till $18 \mathrm{kV}$ and in the neutral shift voltage reduces till $25 \mathrm{kV}$. Two - phase short circuit in the power line overgrow to the three - phase short circuit after the second lightning current impulse. By the process character at the short - circuit place it can be noticed, that till the second lightning current impulse, the electric arc was keeping - on.

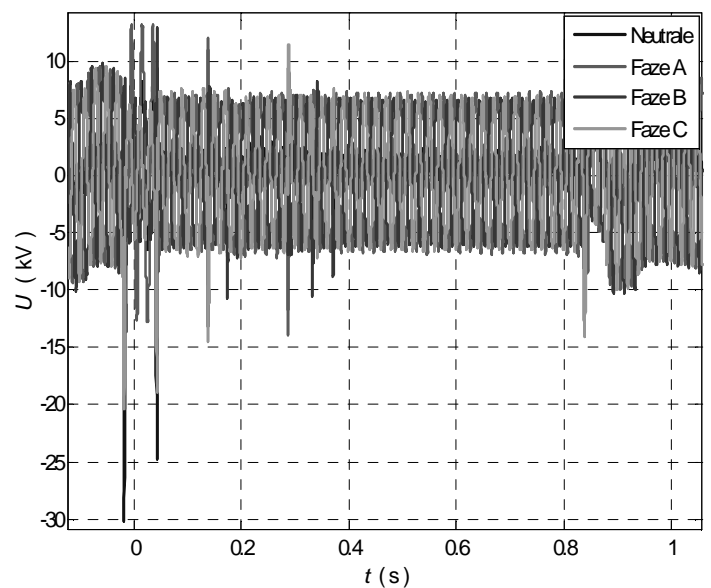

Figure 4. A recorded overvoltage transient induced by a lightning surge.

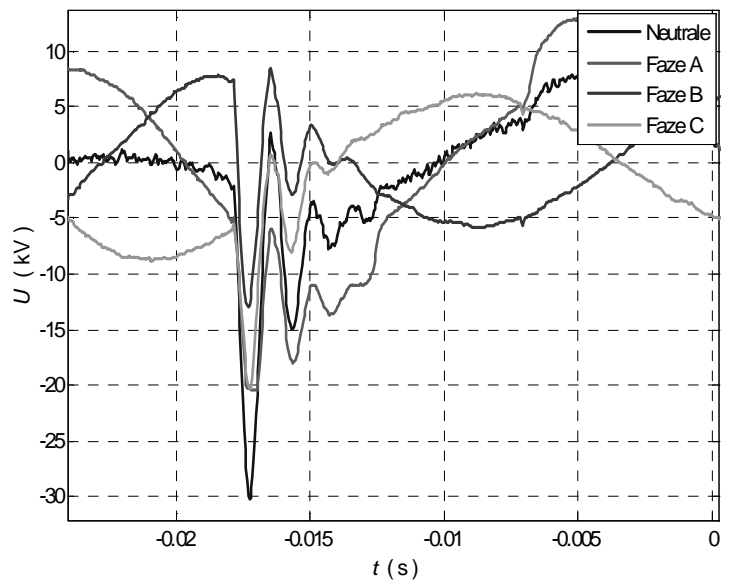

Figure 5. A transient induced by the first lightning surge impulse.

More after $95 \mathrm{~ms}$ the power line was affected by the third lightning surge current impulse. After the third impulse an overvoltage level reached $15 \mathrm{kV}$ and in the neutral shift voltage 
rises only till $13 \mathrm{kV}$. The voltage level had more influence to the power line during this lightning surge impulse.

Following lightning surge current impulses occurred after 36 ms, after $111 \mathrm{~ms}$, after $47 \mathrm{~ms}$ and after $38 \mathrm{~ms}$ (Fig. 7). Whole lightning surge impact to the power line lasts for $395 \mathrm{~ms}$.

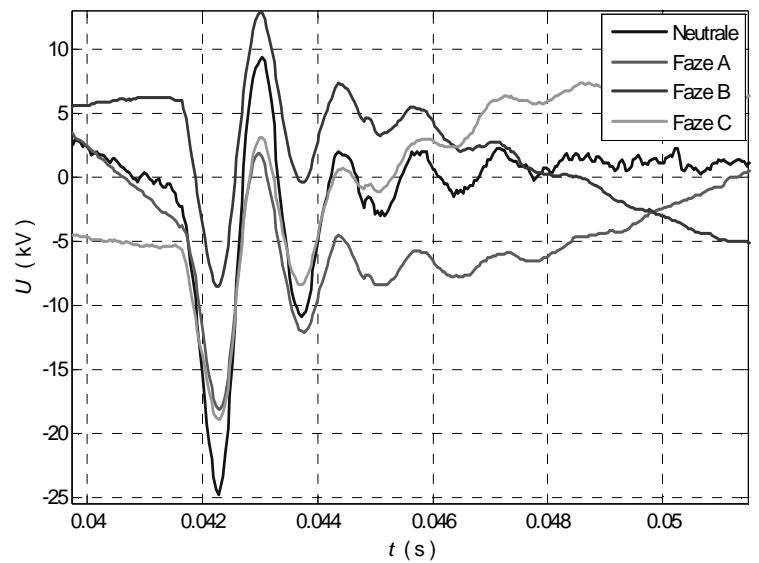

Figure 6 . The 2nd impulse transient of the lightning surge.

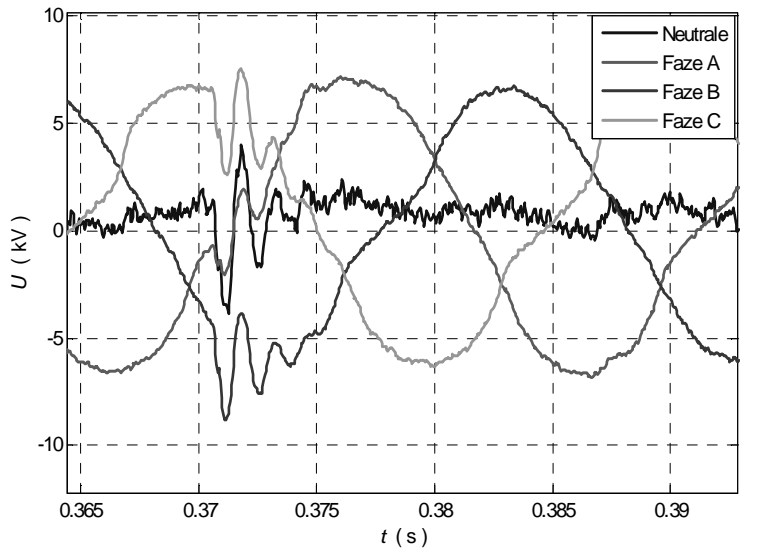

Figure 7. The 7th impulse transient of the lightning surge.

After $1 \mathrm{sec}$, the lightning surge induced overvoltage process results short - circuit, upshot of it the affected power line was disconnected. Disconnection process is shown in Fig. 8.

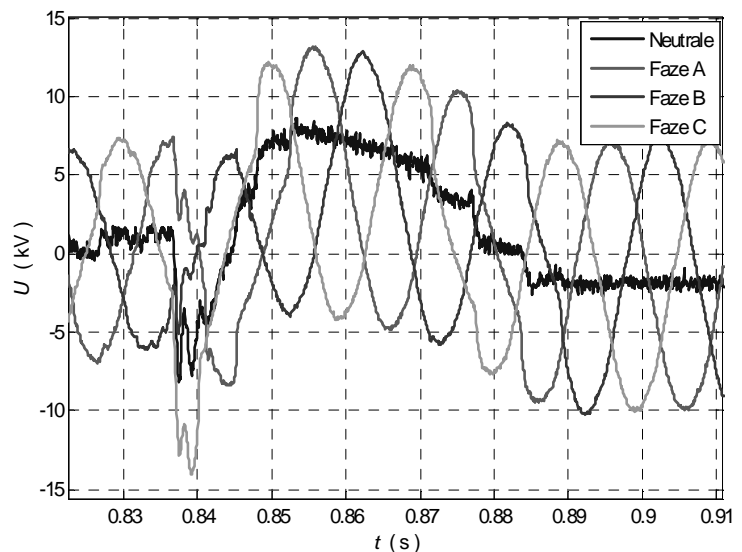

Figure 8 . The transient of the lightning surge induced three - phase short circuit disconnection.
During short - circuit disconnection moment overvoltage level on phase was $14 \mathrm{kV}$ and the neutral voltage shift was $8 \mathrm{kV}$. During such registrations it is possible to compose integral overvoltage impact characteristics [2].

\section{ANALYSIS OF THE LIGHTNING SURGE INDUCED OVERVOLTAGE}

Short transient during every lightning impulse lasts till $400 \mu \mathrm{s}$. Amplitudes of the overvoltage gradually decrease (Fig. 9). The power line phase voltage after the 4th lightning impulse has influence for overvoltage. $U,[\mathrm{kV}]$

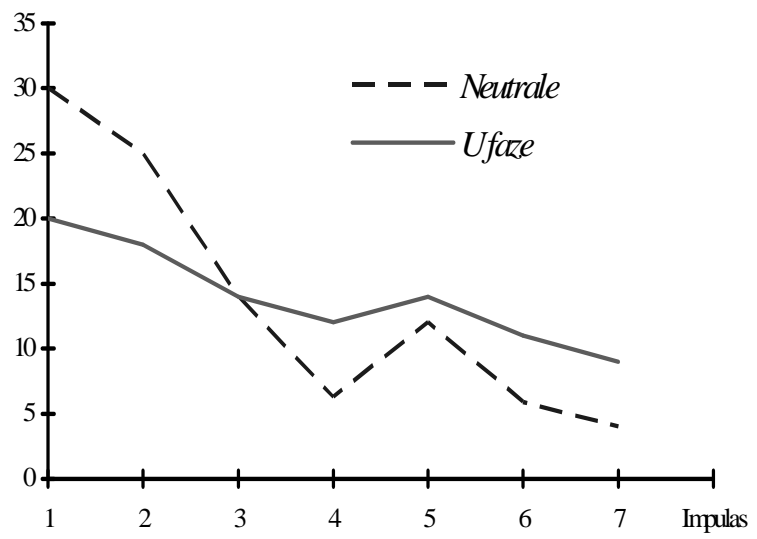

Figure 9. Lightning surge induced overvoltage changes on the phase and neutral lines.

Voltage shift on neutral, impacted by the lightning surge current, was quite great. During the first impulse neutral voltage shift reaches $30 \mathrm{kV}$ at the start of the power line and quite expeditiously sinks because in the lightning strike place one phase fault overpass to the three - phase short - circuit.

\section{OVERVOLTAGE IMPACT INTEGRAL CHARACTERISTICS}

In order to monitor the isolation resource use during overvoltage it is necessary to register overvoltage level and its duration.

The overvoltage impact characteristic registration data during short term single phase earth fault in the insulated neutral $10 \mathrm{kV}$ network is given in the figure 14.

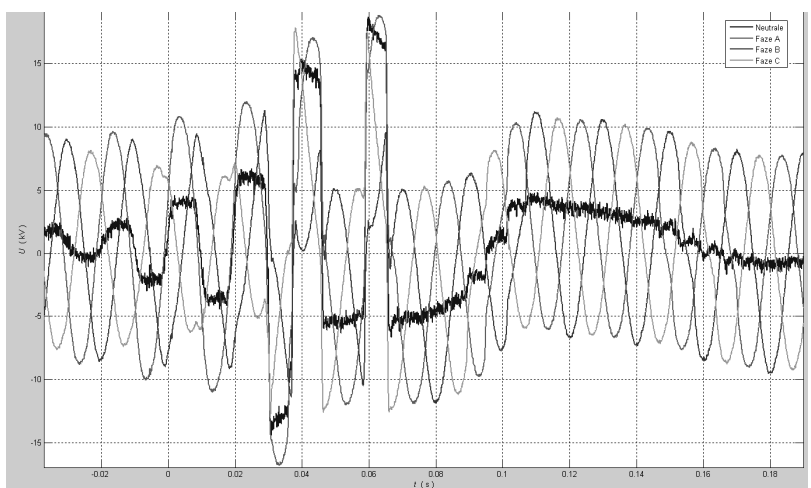

Figure 14. Single phase earth fault in the insulated neutral $10 \mathrm{kV}$ network registration data. 
The overvoltage impact integral characteristic during this fault is given in figure 15 .

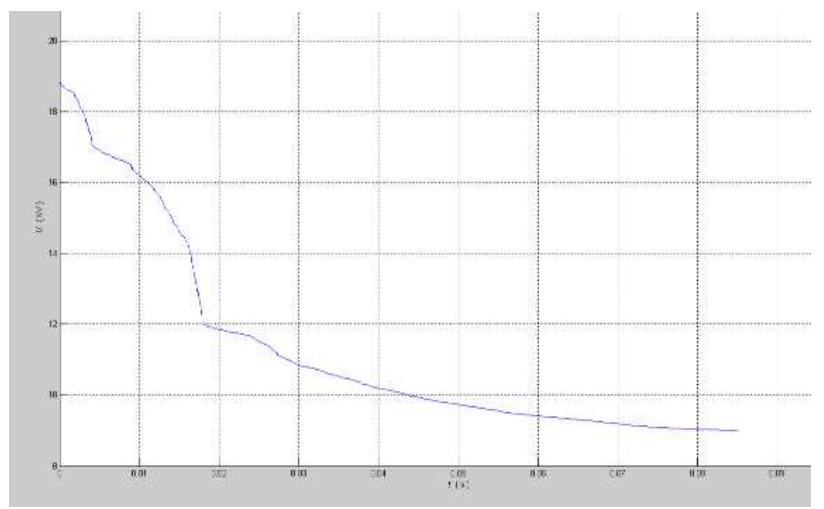

Figure 15. The Integral characteristics of the overvoltage in the insulated neutral 10kV network, during single phase earth fault.

The overvoltage impact integral characteristic during full multifold surge induced transient for the oscillogram given in Fig. 4 is shown in Fig. 16.

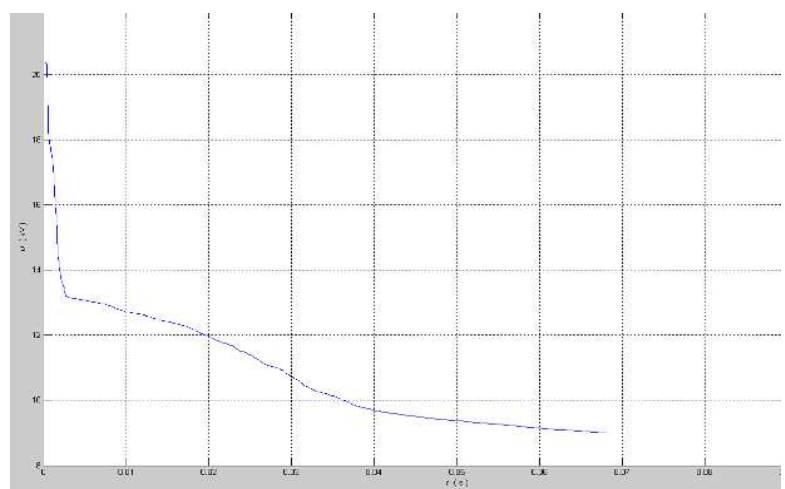

Figure 16. The integral characteristics of a recorded overvoltage transient, induced by a lightning surge.

Analysis of the registered overvoltage characteristics shows what kind of overvoltage are predominantly in the network. The working conditions of electrical equipment can be determined and the maintenance tests or repairs can be carried out [2].

Integral characteristics analysis showed:

1. Maximum duration of the overvoltage was during the earth fault. The duration was $3 \mathrm{~s}$. The maximum amplitude during this process reached $13,4 \mathrm{kV}$. Exceeding of maximum permissible voltage lasted $0,94 \mathrm{~s}$. Calculated zone of overvoltage impact was- $1,3 \mathrm{kV} \cdot \mathrm{s}$.

2. The maximum amplitude voltage registered was during the lightening strike. Duration was 0,1s. The maximum amplitude during this process reached $20,5 \mathrm{kV}$. Exceeding of maximum permissible voltage lasted $0,07 \mathrm{~s}$. Calculated zone of overvoltage impact was $0,126 \mathrm{kV} \cdot \mathrm{s}$.

3. Registration data analysis showed that the data can be grouped by overvoltage assessment zones (see figure 1).

Using experimental registered integral overvoltage characteristics, the relative isolation resource expenditure can be evaluated [2]. This allows to monitor the actual operating conditions for the observed electrical devices.

\section{CONCLUSION}

1. The overvoltage duration and voltage levels can be registered with the special equipment.

2. During analysis of the recorded overvoltage transients, the levels of the overvoltage were determined when lightning surge goes to power line, when lightning current impulse repeats, when power line overpass to the three - phase short - circuit.

3. Experimentally determined biggest neutral voltage shift when lightning strikes to the $10 \mathrm{kV}$ power line. The biggest neutral voltage shift was determined during the first lightning surge impulse and it was $3.11 \mathrm{U}_{\mathrm{mf}}$, during the second impulse $-2.55 \mathrm{U}_{\mathrm{mf}}$.

4. Using experimental registered integral overvoltage characteristics, actual operating conditions for the observed electrical devices can be evaluated.

\section{REFERENCES}

[1] Baublys J., Gudžius S., Jankauskas P., Markevičius L., Morkvėnas A.. Ž.. Apsauga nuo žaibo,. MTD Energetika ISBN 9986-858-28-3: Vilnius, 2006.

[2] Gudžius, Saulius; Markevičius L, Andronis M., Alfonsas N., Algimantas S., Stanioniene R., The Analysis of the Integral Characteristics of the Overvoltage Effect Duration, Proceedings of XVI International Conference on Electromagnetic Disturbances, ISSN 1822-3249: p. $72-$ 77. EMD 2006: September 27-29, 2006

[3] Daunoras, J. Gudžius S. Markevičius L., Andronis M., Alfonsas N., Stanionienè R., Monitoring system of high voltage equipment conditions, Proceedings of 18 International Conference on Electromagnetic Disturbances, ISSN 1822-3249: p. 19-22. EMD 2008: September 25-26, 2008,

[4] Gudžius, S. Markevičius L. Andronis M., Electromagnetic transient processes recognition model in insulated neutral net, Proceedings of XVI International Conference on Electromagnetic Disturbances, ISSN 1822-324. EMD2006: September 27-29, 2006

Vitalijus Gvozdas - 2nd year PhD student in Kaunas Technology University, Faculty of Electrical and Control Engineering, study field: Doctor of Science of Electrical and Electronic Engineering.

Povilas Valatka - department of Electric Power System, Kaunas University of Technolog, Studentu str. 48, LT-53140, Kaunas, Lithuania. 3rd year PhD student in Kaunas Technology University, Faculty of Electrical and Control Engineering, study field: Doctor of Science of Energetic and Thermo Engineering. 